\title{
STUDI AKTIVITAS BIOLOGI SECARA IN SILICO SENYAWA NONIVAMIDE DAN NORDIHYDROCAPSAICIN SEBAGAI ANTI INFLAMASI
}

\author{
Theresia Nona Elfi ${ }^{1}$, Yohanes Nong Bunga ${ }^{1}$, Yohanes Bare ${ }^{1 *}$, \\ Program Studi Pendidikan Biologi, FKIP, Universitas Nusa Nipa Indonesia \\ *Email: bareyohanes@gmail.com
}

\section{Naskah diterima tanggal 25 Juli 2021, naskah disetujui tanggal 23 November 2021, diterbitkan tanggal 30 November 2021}

\begin{abstract}
Capsicum Annum L. is a horticultural plant that is cultivated on a small scale but has health benefits. C. Annum L. is also used for the treatment of toothache, ulcers, anti-parasitic, anti-inflammatory, antitussive and is also used as an antiseptic, appetite. This study aims to analyze the potential of nonivamide and nordihydrocapsaicin compounds as anti-inflammatory. In silico method research studies. Nonivamide compounds (CID: 2998) and Nordihydrocapsaicin (CID: 168836) were obtained from PubChem while COX-2 (6cox) were obtained from the Protein Data Bank. Analysis using HEX 8.0.0 and displayed Discovery studio client 4.1. The interactions that occur between Nonivamide compounds and COX-2 form hydrogen bonds with conventional hydrogen bond types (CYS47) and hydrophobic bonds (LEU152). In addition to hydrogen bonds, there are also nineteen amino acid residues indicating the presence of Van Der Waals forces forming an energy of $-339.48 \mathrm{cal} / \mathrm{mol}$. Nordihydrocapsaicin bond with COX-2 forms a bond at the Pi-Alkyl amino acid residue TRP139 and hydrogen bonds as a donor with the amino acid residue SER143 the bond energy is $-248.47 \mathrm{cal} / \mathrm{mol}$.
\end{abstract}

Keywords: Capsicum Annum L., COX-2, In silico, nonivamide, nordihydrocapsaicin

\section{PENDAHULUAN}

Cabai (Capsicum annum L) merupakan tanaman holtikultura dalam sakala kecil sebagai bahan baku bumbu dapur (Ahmad et al., 2019). Hasil studi literatur menunjukan tanaman cabai mengandung berbagai macam bioaktif kimia. Kandungan utama pada cabai adalah capsaicinoid, selain itu juga terkandung nonivamide dan nordihydrocapsicin (Reyes-Escogido dkk, 2011). Kandungan tersebut diprediksi memiliki khasiat sebagai anti parasite, antitussive, dan anti inflamasi (Sanati dkk., 2018). Selain itu cabai juga memiliki kandungan vitamin C (Tatengkeng, 2019).

Nonivamide yang ada dalam cabai, biasanya diproduksi secara sintesis dan digunakan sebagai bahan tambahan makanan untuk menambah rasa pedas pada bumbu, perasa dan campuran rempahrempah. Nonivamide memiliki efek antioksidan, anti-obesitas, anti-inflamasi, mengurangi asupan energi, meningkatkan metabolisme energi, menurunkan kandungan triasilgliserol serum, dan menghambat adipogenesis melalui aktivasi saluran kation potensial. Nonivamide sering digunakan sebagai pengganti sintetis untuk berbagai macam OC produk lada (Reilly dkk, 2002). Nordihydrocapsaicin adalah capsaicinoid dan analog dan kongen capsaicin dalam cabai (capsicum annum). Nordihydrocapsaicin menyumbang sekitar $7 \%$ dari total campuran capsaicinoids dan memiliki sekitar setengah kepedasan capsaicin.

Inflamasi merupakan kondisi tubuh ketika terjadi perubahan proses fisiologi sehingga terjadinya perubahan produksi protein (Bare et al., 2018; Bare, Sari, et al., 2019a), pencegahan inflamasi dapat dilakukan dengan terapi bahan alam salah satunya dengan kandungan bioaktif dari 
cabai. Tujuan penelitian ini menganalisis aktivitas biologi nonivamide dan nordihydrocapsicin sebagai anti-inflamasi melalui COX-2.

\section{METODE}

Protein COX-2 diunduh dari database Protein Data Bank (PDB) dan senyawa Nonivamide (CID: 2998) dan Nordihydrocapsaicin (CID: 168836) diperoleh dari database PubChem. Program penyaringan virtual PyRx untuk meminimalkan energi senyawa nonamida dan nordihidrokapsaisin. Model protein yang diperoleh dari database dibersihkan dari molekul air dan ligan terikat.

Protein dan ligan dimuat ke dalam perangkat lunak HEX8.0.0 dan perangkat dijalankan. Hasilnya disimpan sebagai file pdb. Hasil docking ligan dan protein dianalisis dan divisualisasikan dengan bantuan software Discovery Studio Client 4.1. Analisis yang dilakukan adalah residu asam amino, ikatan hidrogen dan energi ikatan yang terbentuk antara ligan dengan protein (Bare \& Sari, 2021).

\section{HASIL DAN PEMBAHASAN \\ Interaksi Senyawa Nonivamide Sebagai Inhibitor COX-2}

Senyawa nonivamide merupakan salah satu komponen yang terdapat dalam cabai merah besar (Capsicum annum L.).
Molecular docking Nonivamide dan COX-2 membentuk ikatan hidrogen dengan tipe ikatan hidrogen konvensional (CYS47) dan ikatan hidrofobik (LEU152) sisanya membentuk gaya Van Der Waals (ARG44, ARG469, TYR130, GLU46, GLYs45, PRO153, ASN34, GLY135, ALA156, ASP157, GLU465, ASN39, CYS41, PRO40, CYS 36, PRO154, TYR136, TYR134, HIS133) Energi ikatan sebesar $339.48 \mathrm{cal} / \mathrm{mol}$. Ikatan hidrogen dapat terbentuk meskipun jarak antara ligan dan reseptor cukup jauh (Andriani, 2018).

\section{Interaksi}

COX-2-nonivamide menunjukkan nilai dan memiliki satu cincin aromatic (Gambar 1c). Senyawa nonivamide juga berfungsi sebagai donor dan acceptor terhadap COX-2 (Gambar 1d). Senyawa nonivamide cenderung bersifat netral (Gambar 1e dan Gambar 1g). Interaksi antara COX-2 dengan nonivamide menunjukkan tingkat hidrofobisitas yang (Gambar 1f). Nilai Solvent Accessible Surfance (SAS) pada permukaan nonivamide cukup tinggi (Gambar $1 \mathrm{~h}$ ). Tampilan interaksi ini memberikan informasi bahwa ikatan antar ligand dan protein memiliki nilai interaksi yang sangat tinggi terhadap pengikatan sisi aktif dari protein COX-2 (Bare, Sari, dkk 2019; Santoso dan Atmajaya, 2016).

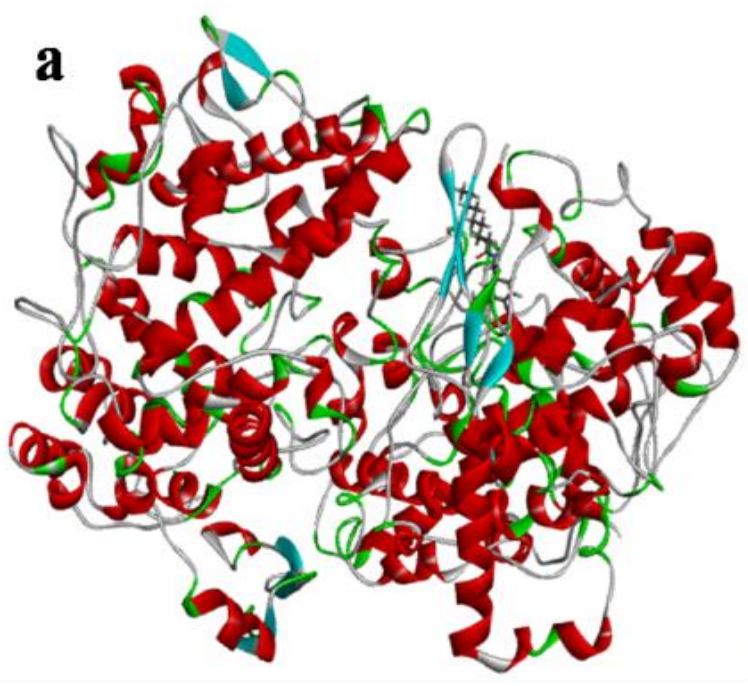

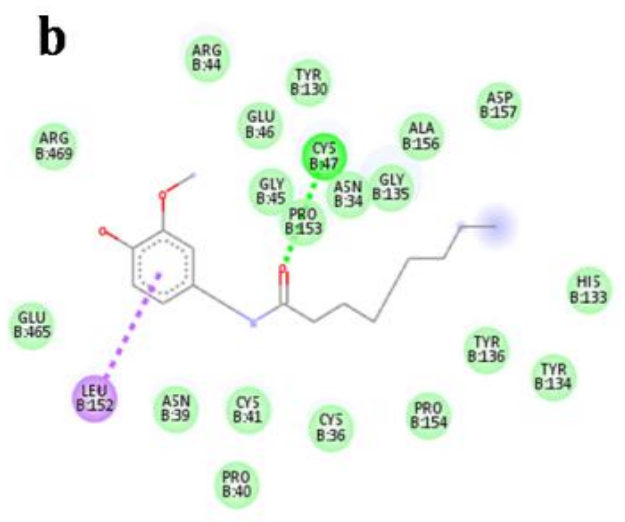

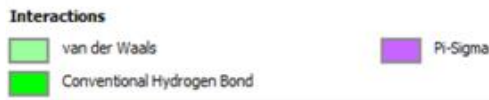



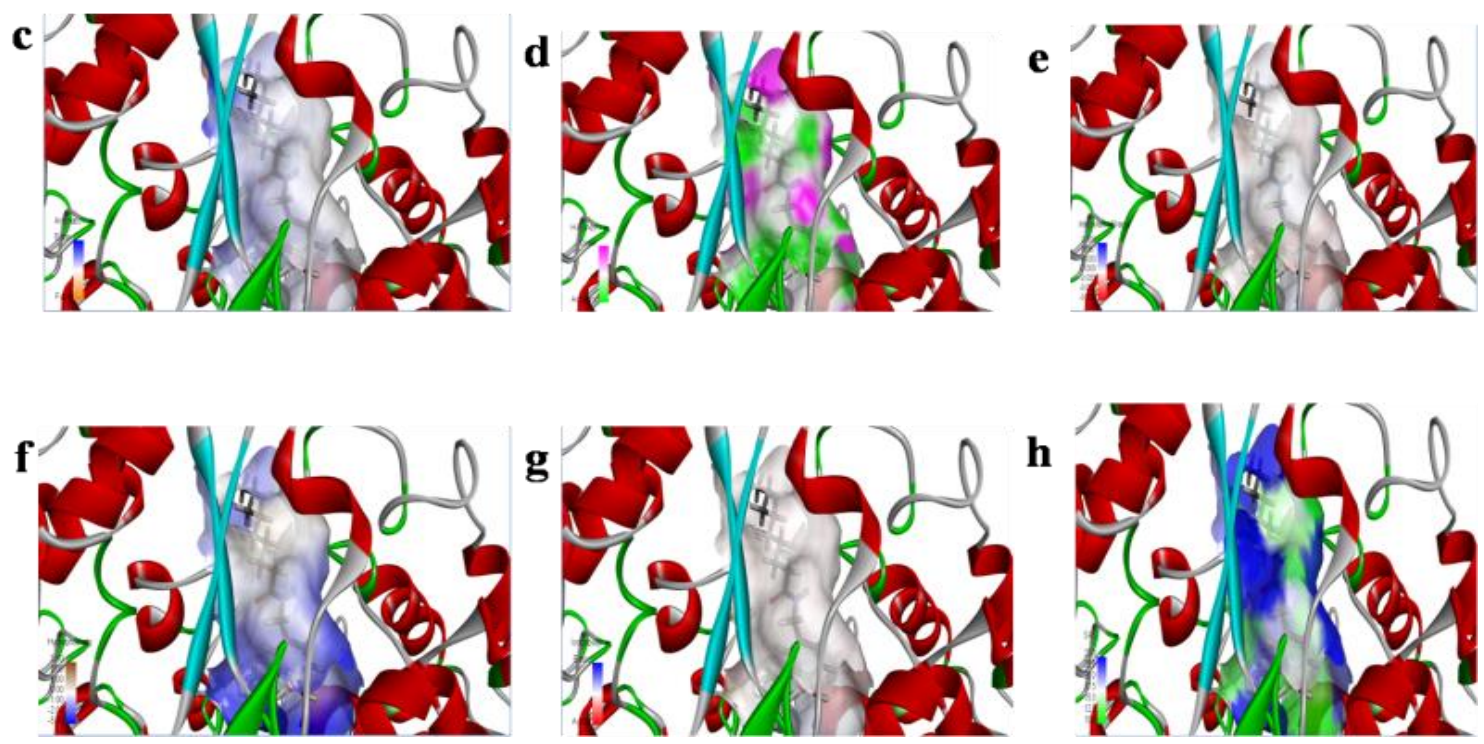

Gambar 1. Interaksi antara Nonivamide dan COX-2 a.interaksi struktur 3D b.interaksi struktur 2D. c.aromatic, d.H- Bond, e.Charge, f. Hydropobic, g. Ionizability, h. SAS

Tabel 1. Interaksi Senyawa Nonivamide dan Protein COX-2

\begin{tabular}{|c|c|c|c|c|c|c|c|}
\hline $\begin{array}{l}\text { Com- } \\
\text { plexes }\end{array}$ & $\begin{array}{c}\text { Energy } \\
(\mathrm{Cal} / \\
\mathrm{mol}) \\
\end{array}$ & Name & $\begin{array}{l}\text { Distan- } \\
\text { ce }\end{array}$ & Category & Types & $\begin{array}{c}\text { From } \\
\text { Chemistry }\end{array}$ & $\begin{array}{c}\text { To } \\
\text { Chemistry }\end{array}$ \\
\hline \multirow{20}{*}{$\begin{array}{l}\text { Noniva } \\
\text { mide - } \\
\text { COX-2 }\end{array}$} & \multirow{20}{*}{-339.48} & $\begin{array}{l}\text { B:ARG44:HH22 - } \\
\text { B:TYR122:O }\end{array}$ & 3,0379 & Hydrogen Bond & $\begin{array}{l}\text { Conventional } \\
\text { Hydrogen Bond }\end{array}$ & H-Donor & H-Acceptor \\
\hline & & $\begin{array}{l}\text { B:GLU46:HN - } \\
\text { B:ASP58:O }\end{array}$ & 2,2403 & Hydrogen Bond & $\begin{array}{l}\text { Conventional } \\
\text { Hydrogen Bond }\end{array}$ & H-Donor & H-Acceptor \\
\hline & & $\begin{array}{l}\text { B:GLY45:HN - } \\
\text { B:GLN42:O }\end{array}$ & 2,0513 & Hydrogen Bond & $\begin{array}{l}\text { Conventional } \\
\text { Hydrogen Bond }\end{array}$ & H-Donor & H-Acceptor \\
\hline & & $\begin{array}{l}\text { B:ASN34:HN - } \\
\text { B:ASP158:OD2 }\end{array}$ & 2,0737 & Hydrogen Bond & $\begin{array}{l}\text { Conventional } \\
\text { Hydrogen Bond }\end{array}$ & H-Donor & H-Acceptor \\
\hline & & $\begin{array}{l}\text { B:CYS36:HN - } \\
\text { B:ASN34:OD1 }\end{array}$ & 1,9411 & Hydrogen Bond & $\begin{array}{l}\text { Conventional } \\
\text { Hydrogen Bond }\end{array}$ & H-Donor & H-Acceptor \\
\hline & & $\begin{array}{l}\text { B:ASN39:HN - } \\
\text { B:CYS36:O }\end{array}$ & 1,9725 & Hydrogen Bond & $\begin{array}{l}\text { Conventional } \\
\text { Hydrogen Bond }\end{array}$ & H-Donor & H-Acceptor \\
\hline & & $\begin{array}{l}\text { B:ASN39:HD21 - } \\
\text { B:CYS36:O }\end{array}$ & 2,928 & Hydrogen Bond & $\begin{array}{l}\text { Conventional } \\
\text { Hydrogen Bond }\end{array}$ & H-Donor & H-Acceptor \\
\hline & & $\begin{array}{l}\text { B:TYR134:HN - } \\
\text { B:ASN131:O }\end{array}$ & 1,8249 & Hydrogen Bond & $\begin{array}{l}\text { Conventional } \\
\text { Hydrogen Bond }\end{array}$ & H-Donor & H-Acceptor \\
\hline & & $\begin{array}{l}\text { B:HIS133:HN - } \\
\text { B:ASN131:OD1 }\end{array}$ & 1,9667 & Hydrogen Bond & $\begin{array}{l}\text { Conventional } \\
\text { Hydrogen Bond }\end{array}$ & H-Donor & H-Acceptor \\
\hline & & $\begin{array}{l}\text { B:GLN42:HN - } \\
\text { B:PRO40:O }\end{array}$ & 3,0365 & Hydrogen Bond & $\begin{array}{l}\text { Conventional } \\
\text { Hydrogen Bond }\end{array}$ & H-Donor & H-Acceptor \\
\hline & & $\begin{array}{l}\text { B:CYS159:HN - } \\
\text { B:ALA156:O }\end{array}$ & 1,7894 & Hydrogen Bond & $\begin{array}{l}\text { Conventional } \\
\text { Hydrogen Bond }\end{array}$ & H-Donor & H-Acceptor \\
\hline & & $\begin{array}{l}\text { B:GLN461:HE21 } \\
\text { - B:PRO153:O }\end{array}$ & 2,1661 & Hydrogen Bond & $\begin{array}{l}\text { Conventional } \\
\text { Hydrogen Bond }\end{array}$ & H-Donor & H-Acceptor \\
\hline & & $\begin{array}{l}\text { B:LYS459:HZ3 - } \\
\text { B:ALA156:O }\end{array}$ & 2,2458 & Hydrogen Bond & $\begin{array}{l}\text { Conventional } \\
\text { Hydrogen Bond }\end{array}$ & H-Donor & H-Acceptor \\
\hline & & $\begin{array}{l}\text { B:GLU465:HN - } \\
\text { B:SER462:O }\end{array}$ & 2,439 & Hydrogen Bond & $\begin{array}{l}\text { Conventional } \\
\text { Hydrogen Bond }\end{array}$ & H-Donor & H-Acceptor \\
\hline & & $\begin{array}{l}\text { B:GLU465:HN - } \\
\text { B:SER462:OG }\end{array}$ & 2,5345 & Hydrogen Bond & $\begin{array}{l}\text { Conventional } \\
\text { Hydrogen Bond }\end{array}$ & H-Donor & H-Acceptor \\
\hline & & $\begin{array}{l}\text { B:ARG469:HN - } \\
\text { B:GLU465:O }\end{array}$ & 1,9588 & Hydrogen Bond & $\begin{array}{l}\text { Conventional } \\
\text { Hydrogen Bond }\end{array}$ & H-Donor & H-Acceptor \\
\hline & & $\begin{array}{l}\text { B:ARG469:HE - } \\
\text { B:ARG469:O }\end{array}$ & 1,8777 & Hydrogen Bond & $\begin{array}{l}\text { Conventional } \\
\text { Hydrogen Bond }\end{array}$ & H-Donor & H-Acceptor \\
\hline & & $\begin{array}{l}\text { B:ARG150:HN - } \\
\text { B:TYR130:O }\end{array}$ & 2,7766 & Hydrogen Bond & $\begin{array}{l}\text { Conventional } \\
\text { Hydrogen Bond }\end{array}$ & H-Donor & H-Acceptor \\
\hline & & $\begin{array}{l}\text { B:CYS41:SG - } \\
\text { B:TYR55 }\end{array}$ & 5,2948 & Other & Pi-Sulfur & Sulfur & Pi-Orbitals \\
\hline & & $\begin{array}{l}\text { B:CYS47:HN - } \\
\text { :LIG1:O }\end{array}$ & 2,8156 & Hydrogen Bond & $\begin{array}{l}\text { Conventional } \\
\text { Hydrogen Bond }\end{array}$ & H-Donor & H-Acceptor \\
\hline
\end{tabular}


Senyawa Nonivamide berpotensi sebagai terapi anti-inflamasi COX-2, Hal ini dibuktikan melalui pengikatan 19 residu asam amino (Tabel 2). Nilai afinitas yang rendah akan menguatkan interaksi antara ligan dan protein. Interaksi ligan dan protein yang yang kuat akan menstabilkan kompleks ligand-protein. Hidrofobisitas yang rendah berbanding terbalik dengan jumlah ikatan hidrofobisitas dan meningkatkan permeabilitas senyawa pada membran sel (Bare, Kuki, dkk, 2019).

\section{Interaksi Senyawa Nordihydrocapsaicin Sebagai Inhibitor COX-2}

Senyawa Nordihydrocapsaicin diinteraksikan dengan COX-2 membentuk sejumlah ikatan residu asam amino TRP139 bersifat Pi-Alkyl dan ikatan hidrogen sebagai donor dengan Residu asam amino SER143, dan gaya Van der Waals(GLY223, LYS333, LEU145, GLU140, ASP229, GLY225, ASN144, PHE142, SER146, LEU238, THR237 ) (Gambar 2b) menghasilkan energi -248.47 $\mathrm{cal} / \mathrm{mol}$ (Tabel 2). Interaksi antara COX-2 dengan nordihydrocapsaicin menunjukkan nilai aromatic (Gambar 2c). Senyawa nordihydrocapsaicin juga berfungsi sebagai donor dan acceptor terhadap COX-2 (Gambar 2d). Senyawa nordihydrocapsaicin cenderung bersifat netral (Gambar 2e dan Gambar 2g). Interaksi antara COX-2 dengan nordihydrocapsaicin menunjukkan tingkat hidrofobisitas yang (Gambar 2f). Nilai Solvent Accessible Surfance (SAS) pada permukaan nordihydrocapsaicin cukup tinggi (Gambar 2h).

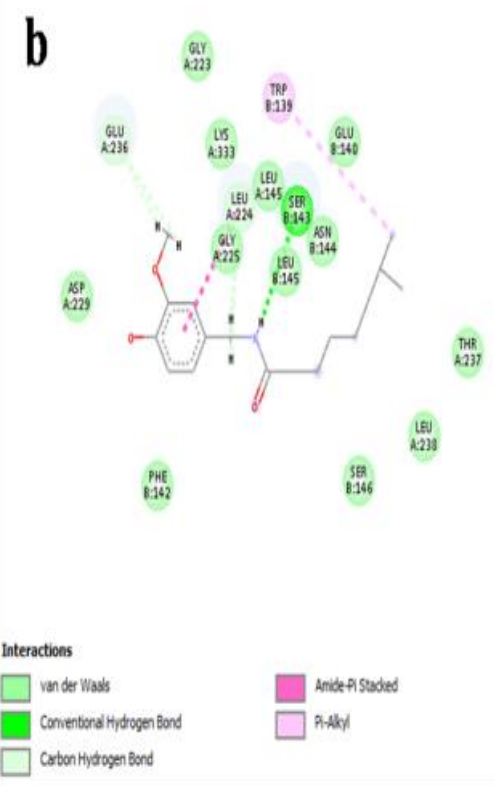



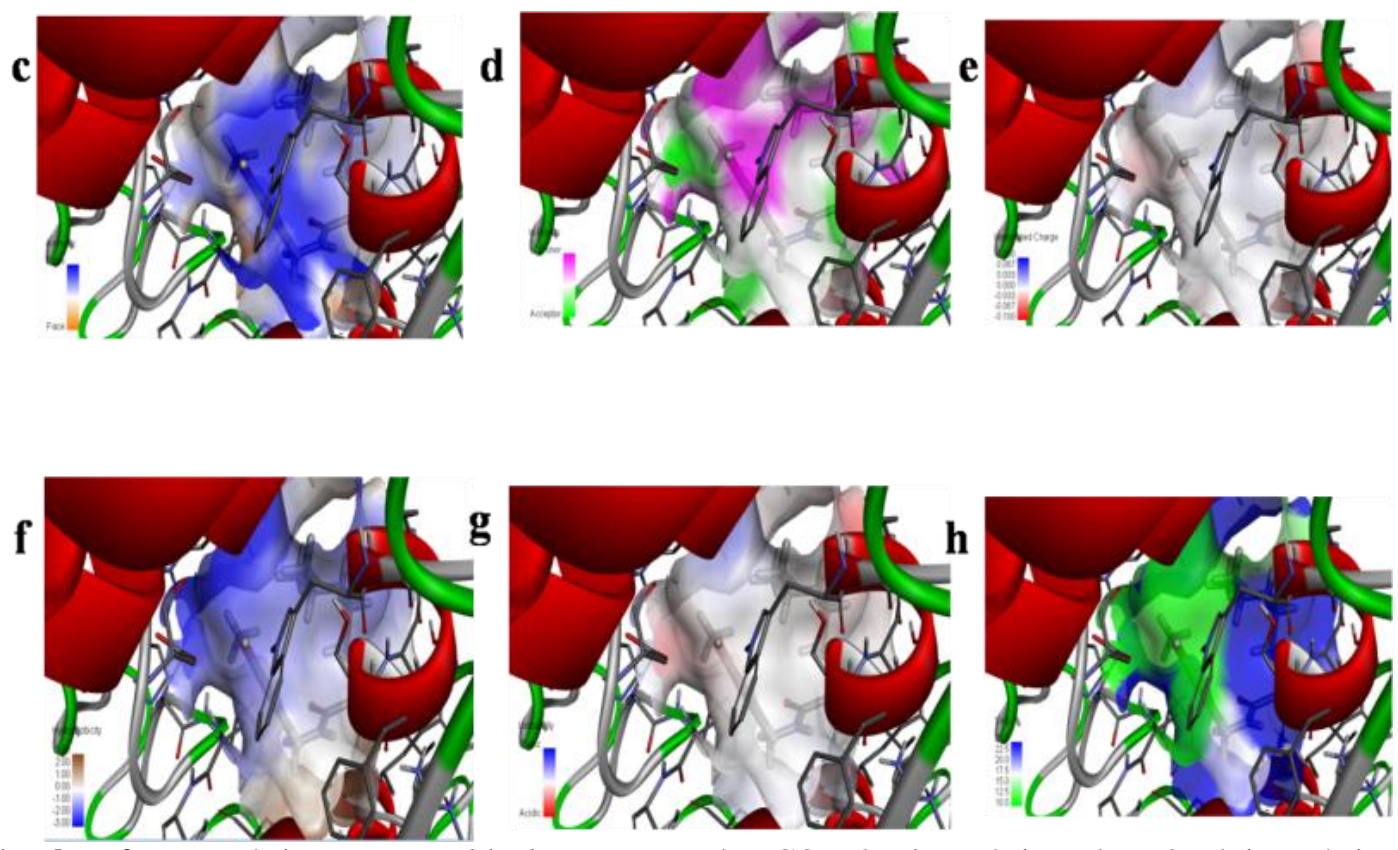

Gambar 2. Interaksi antara Nordihydrocapsaicin dan COX-2 a.interaksi struktur 3D b.interaksi struktur 2D. c.aromatic, d.H- Bond, e.Charge, f. Hydropobic, g. Ionizability, h. SAS

Nilai negatif yang diperoleh menunjukan ligan dan reseptor berlangsung secara spontan (Andriani, 2018; Tiring et al., 2019). Nordihydrocapsaicin memiliki peran sebagai inhibitor $\mathrm{COX}-2$ dengan menstimulus penghambatan pada 11 residu asam amino COX-2. Sisi penggerak COX2 dalam asam amino residu, yang terikat dengan ikatan hidrogen. Jalur inflamasi berperan oleh $\mathrm{COX}-2$ dan asam klorogenat menonaktifkan COX-2 oleh interaksi aktif (domain sisi aktif COX-2). COX-2 adalah enzim pusat di biosintesis prostaglandin ini diaktifkan oleh rangsangan inflamasi, seperti sitokin dan lipopolisakarida.

Tabel 2. Interaksi Senyawa Nordihydrocapsaicin dan Protein COX-2

\begin{tabular}{|c|c|c|c|c|c|c|c|}
\hline $\begin{array}{c}\text { Compl } \\
\text { exe }\end{array}$ & $\begin{array}{c}\text { Energy } \\
\text { (Cal/ } \\
\text { Mol) } \\
\end{array}$ & Name & Distance & Category & Types & $\begin{array}{c}\text { From } \\
\text { Cemistry }\end{array}$ & $\begin{array}{c}\text { To } \\
\text { Chemistry }\end{array}$ \\
\hline \multirow{7}{*}{$\begin{array}{l}\text { Nodihy } \\
\text { drocaps } \\
\text { aicin- } \\
\text { COX-2 }\end{array}$} & -248.47 & $\begin{array}{l}\text { A:HIS226:C } \\
\text { D2 - } \\
\text { A:GLY223:O }\end{array}$ & 3,0224 & $\begin{array}{l}\text { Hydrogen } \\
\text { Bond }\end{array}$ & $\begin{array}{l}\text { Carbon Hydrogen } \\
\text { Bond }\end{array}$ & H-Donor & H-Acceptor \\
\hline & & $\begin{array}{l}\text { A:LYS333:C } \\
\text { E - } \\
\text { A:ASP229:O }\end{array}$ & 3,26448 & $\begin{array}{l}\text { Hydrogen } \\
\text { Bond }\end{array}$ & $\begin{array}{l}\text { Carbon Hydrogen } \\
\text { Bond }\end{array}$ & H-Donor & H-Acceptor \\
\hline & & $\begin{array}{l}\text { A:LEU145 - } \\
\text { A:LEU224 }\end{array}$ & 5,27668 & Hydrophobic & Alkyl & Alkyl & Alkyl \\
\hline & & $\begin{array}{l}\text { A:GLY225:C } \\
\text { A - } \\
\text { A:ASP229:O } \\
\text { D2 }\end{array}$ & 3,64722 & $\begin{array}{l}\text { Hydrogen } \\
\text { Bond }\end{array}$ & $\begin{array}{l}\text { Carbon Hydrogen } \\
\text { Bond }\end{array}$ & H-Donor & H-Acceptor \\
\hline & & $\begin{array}{l}\text { A:GLY225:C } \\
\text { A - } \\
\text { A:ASP229:O } \\
\text { D2 }\end{array}$ & 3,64722 & $\begin{array}{l}\text { Hydrogen } \\
\text { Bond }\end{array}$ & $\begin{array}{l}\text { Carbon Hydrogen } \\
\text { Bond }\end{array}$ & H-Donor & H-Acceptor \\
\hline & & $\begin{array}{l}\text { A:LEU238:C } \\
\text { D2 - } \\
\text { A:HIS242 }\end{array}$ & 3,44421 & Hydrophobic & Pi-Sigma & $\mathrm{C}-\mathrm{H}$ & Pi-Orbitals \\
\hline & & $\begin{array}{l}\text { B:LEU145:H } \\
- \\
\text { B:SER143:O }\end{array}$ & 2,86998 & $\begin{array}{l}\text { Hydrogen } \\
\text { Bond }\end{array}$ & $\begin{array}{l}\text { Conventional } \\
\text { Hydrogen Bond }\end{array}$ & H-Donor & H-Acceptor \\
\hline
\end{tabular}




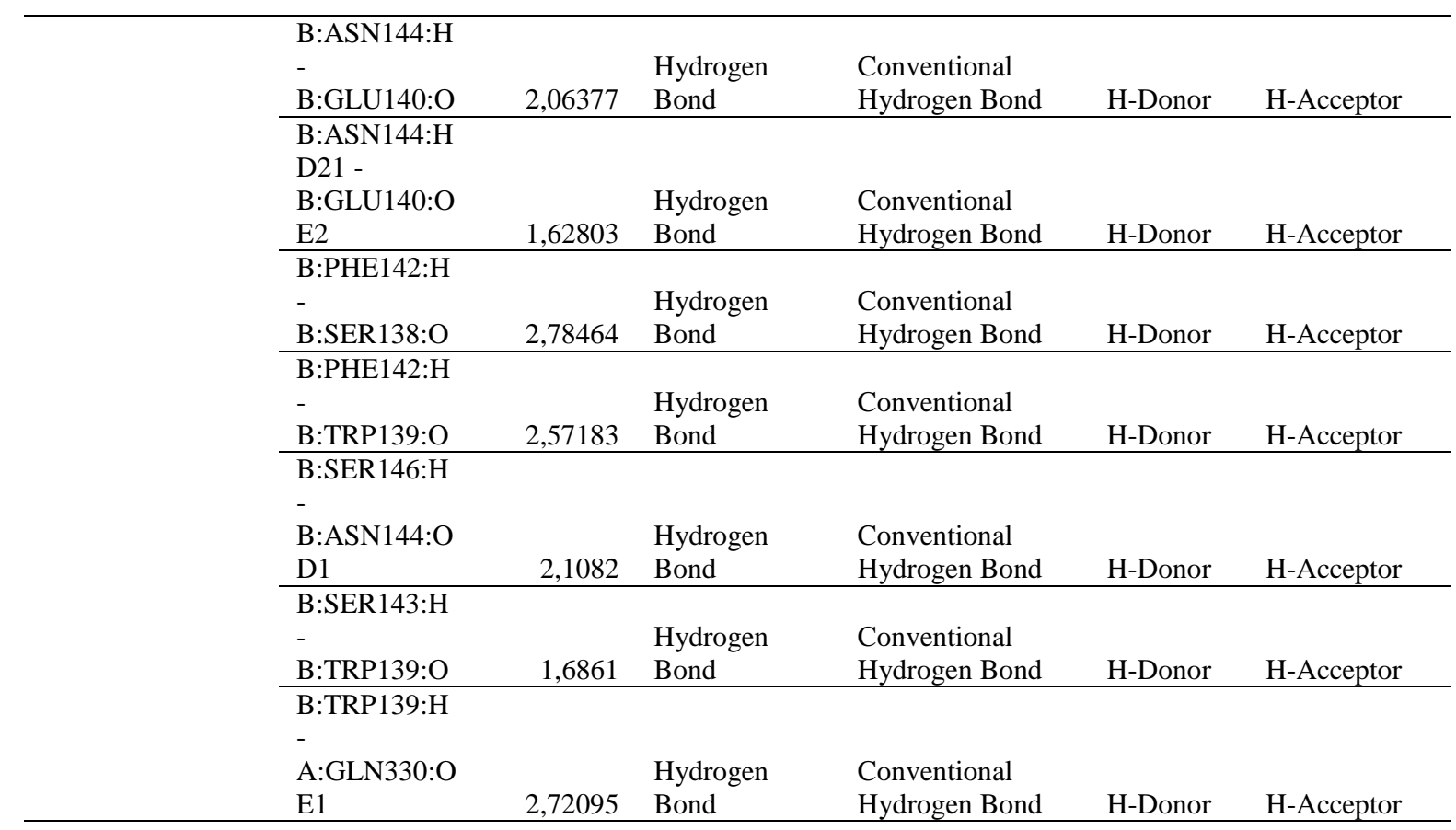

Di dalam sel sitokin dan lipopolisakarida jalur metabolisme, COX-2 diinduksi oleh produksi prostaglandin berimplikasi pada peningkatan peradangan, renovasi jaringan matriks, perkembangan fibrosis dan perluasan tumor genesis (Bare, Sari, dkk, 2019). Ikatan elektrostatik adalah ikatan ionic, merupakan jembatan garam atau ion antara gugus bermuatan berperan stabilitas protein dan berperan dalam pengikatan ligan atau substat (Endah Wulandari \& Hendarmin, 2005; Sari et al., 2019)

\section{SIMPULAN}

Interkasi senyawa nonivamide dan COX-2 membentuk beberapa ikatan yaitu, ikatan hidrogen dengan tipe hidrogen konvensional, ikatan hidrofobik dan juga ikatan Van Der Waals. Energi ikatan yang terbentuk adalah $-339.48 \mathrm{cal} / \mathrm{mol}$. Sementara itu, interaksi senyawa nordihydrocapsaicin dan COX-2 membentuk sejumlah ikatan yang bersifat pi-alkyl, ikatan hydrogen dan adanya gaya Van Der Waals. Energi ikatan yang terbentuk adalah $-248.47 \mathrm{cal} / \mathrm{mol}$.

\section{DAFTAR PUSTAKA}

Ahmad, N. I., Bunga, Y. N., \& Bare, Y. (2019). Etnobotani Tanaman Cabai Merah Keriting (Capsicum Annum L.) Di Desa Waiwuring, Kecamatan Witihama Kabupaten Flores Timur. Spizaetus: Jurnal Biologi dan Pendidikan Biologi, 2(2), 10.

Andriani. (2018). Prediksi Senyawa Bioaktif Dari Tanamann Sanrego (Lunasia amara Blanco) Sebagai Inhibitor Enzim Siklooksigenase -2 (COX-2) Melalui Pendekatan Molecular Docking. 1.

Bare, Y., Kuki, A. D., Rophi, A. H., \& Candrakirana, G. (2019). Prediksi Asam Kuinat Sebagai Anti-Inflamasi Terhadap COX-2 Secara Virtual Virtual Prediction of Quinic Acid As Anti-Inflammation of COX-2. 4, 6.

Bare, Y., Marhendra, A., Sasase, T., \& Fatchiyah, F. (2018). Differential Expression of IL-10 Gene and Protein in Target Tissues of Rattus Norvegicus Strain Wistar Model Type 2 Diabetes Mellitus (T2DM). Acta Informatica Medica, 26(2), 8792.

https://doi.org/10.5455/aim.2018.26.8 7-92 
Bare, Y., \& Sari, D. R. T. (2021). Pengembangan Lembar Kerja Mahasiswa (LKM) Berbasis Inkuiri Pada Materi Interaksi Molekuler. BioEdUIN, $\quad 11(1), \quad 8$. https://doi.org/10.15575/bioeduin.v11 i1.12077

Bare, Y., Sari, D. R. T., Rachmad, Y. T., Krisnamurti, G. C., \& Elizabeth, A. (2019a). In Silico Insight the Prediction of Chlorogenic Acid in Coffee through Cyclooxygenase-2 (COX2) Interaction. Biogenesis: Jurnal Ilmiah Biologi, 7(2), 100-105. https://doi.org/10.24252/bio.v7i2.984 7

Bare, Y., Sari, D. R. T., Rachmad, Y. T., Krisnamurti, G. C., \& Elizabeth, A. (2019b). In Silico Insight the Prediction of Chlorogenic Acid in Coffee through Cyclooxygenase-2 (COX2) Interaction. Biogenesis: Jurnal Ilmiah Biologi, 7(2), 100-105. https://doi.org/10.24252/bio.v7i2.984 7

Bare, Y., Sari, D. R. T., Rachmad, Y. T., Krisnamurti, G. C., \& Elizabeth, A. (2019c). In Silico Insight the Prediction of Chlorogenic Acid in Coffee through Cyclooxygenase-2 (COX2) Interaction. Biogenesis: Jurnal Ilmiah Biologi, 7(2). https://doi.org/10.24252/bio.v7i2.984 7

Endah Wulandari, \& Hendarmin, L. A. (2005). Biokimia dan biomolekuler.

Reilly, A., Crouch, D. J., Yost, G. S., \& Fatah, A. A. (2002). Determinationof Capsaicin,Nonivamide, and

Dihydrocapsaicinin Bloodand Tissueby Liquid ChromatographyTandemMassSpectrometry. Journal of Analytical Toxicology, 26, 7.

Reyes-Escogido, M., GonzalezMondragon, E. G., \& VazquezTzompantzi, E. (2011). Chemical and Pharmacological Aspects of Capsaicin. Molecules, 16(2), 12531270. https://doi.org/10.3390/molecules 160 21253

Sanati, S., Razavi, B. M., \& hosseinzadeh, hossein. (2018). A review of the effects of Capsicum annuum L. and its constituent, capsaicin, in metabolic syndrome. Iranian Journal of Basic Medical Sciences, 21(5). https://doi.org/10.22038/ijbms.2018.2 5200.6238

Santoso, B., \& Atmajaya, T. E. (2016). KAJIAN DOCKING SENYAWA 4[(Z)-N-(4-

hidroksifenil)carboksimidoil]-2-

metoksifenol SEBAGAI INHIBITOR

COX-2

MENGGUNAKAN

PLANTS. Conference: Prosiding Seminar Nasional Kimia UNJANIHKI 2016, 9.

Sari, D. R. T., Cairns, J. K., Safitri, A., \& Fatchiyah, F. (2019). Virtual Prediction of the Delphinidin-3-Oglucoside and Peonidin-3-Oglucoside as Anti-inflammatory of TNF- $\alpha$ Signaling. Acta Informatica Medica, 27(3), 152. https://doi.org/10.5455/aim.2019.27.1 52-157

Tatengkeng, M. A. (2019). Kadar Vitamin C Cabai Rawit (Capsicum frutescens L) Hasil Ozonasi Selama Penyimpanan Suhu Ruang. Pasundan Food Technology Journal, 6(2), 102. https://doi.org/10.23969/pftj.v6i2.129 6

Tiring, S. S. N. D., Bare, Y., Maulidi, A., S, M., \& Nugraha, F. A. D. (2019). Studi In Silico: Prediksi Potensi 6shogaol dalam Zingiber officinale sebagai Inhibitor JNK. Al-Kimia, $7(2)$, 147-153. https://doi.org/10.24252/alkimia.v7i2.10638 